\title{
Klasifikasi Jenis Pisang Berdasarkan Fitur Warna, Tekstur, Bentuk Citra Menggunakan SVM dan KNN
}

\author{
Classification of Banana Types Based on Color, Texture, Image Shape Features Using SVM \\ and $K N N$
}

\author{
Yusuf Eka Yana ${ }^{1}$, Nur Nafi'iyah*2 \\ ${ }^{1,2}$ Teknik Informatika, Fakultas Teknik, Universitas Islam Lamongan \\ ${ }_{1,2}$ Lamongan, Indonesia \\ e-mail: ${ }^{1}$ yusufeka678@gmail.com, *2mynaff26@gmail.com
}

\begin{abstract}
Abstrak - Di Indonesia mempunyai beragam jenis tanaman, buah yang dapat ditanam di berbagai daerah Indonesia. Contohnya buah Pisang mempunyai beragam jenis Pisang, dan beberapa masyarakat kurang memahami jenis-jenis Pisang yang ada di Indonesia. Dengan kondisi itu maka kami akan melakukan suatu penelitian terkait mengklasifikasikan jenis Pisang berbasis komputer. Tujuan penelitian ini, yaitu mengidentifikasi atau mengklasifikasi jenis Pisang berdasarkan fitur citra (warna, tekstur, bentuk) dengan algoritma SVM dan KNN. Data yang digunakan adalah citra Pisang total 399, yang diklasifikasi menjadi 7 jenis, Pisang ambon, Pisang kepok, Pisang susu, Pisang raja, Pisang mas, Pisang raja nangka, Pisang cavendish. Dari citra Pisang diambil fitur warna nilai rata-rata $R G B$, standar deviasi RGB, skewness RGB, entropy RGB. Fitur tekstur nilai rata-rata citra grayscale, standar deviasi grayscale, dan gray level cooccurance matrix (kontras, energi, korelasi, homogeneity). Serta fitur bentuk dari citra biner nilai area, perimeter, metric, major axis, minor axis, eccentricity. Hasil ujicoba menunjukkan algoritma SVM nilai akurasi mengklasifikasi jenis Pisang secara berturut-turut dari fitur warna, tekstur, bentuk adalah 41,67\%, 33,3\%, 8,3\%. Dan hasil klasifikasi jenis Pisang dengan algoritma KNN, nilai K terbaik adalah 2 pada fitur warna 55,95\%, fitur tekstur 58,33\%, dan fitur bentuk 45,24\%.
\end{abstract}

Kata kunci-fitur citra; jenis klasifikasi; KNN; SVM.

\begin{abstract}
In Indonesia, there are various types of plants, fruits that can be planted in various regions of Indonesia. For example, Bananas have various types of bananas, and some people do not understand the types of bananas in Indonesia. With these conditions, we will conduct a study related to classifying computerbased bananas. The purpose of this study is to identify or classify bananas based on image features (color, texture, shape) with SVM and KNN algorithms. The data used are the image of a total of 399 bananas, which are classified into 7 types, Banana Ambon, Banana Banana, Milk Banana, Banana Banana, Banana Banana, Banana Banana Jackfruit, Cavendish Banana. From the image of Bananas the color features of RGB mean values, RGB standard deviation, RGB skewness, entropy $R G B$ are taken. Texture features average values of grayscale images, grayscale standard deviations, and gray level co-occurance matrix (contrast, energy, correlation, homogeneity). And the shape features of binary images are area, perimeter, metric, major axis, minor axis, eccentricity values. The test results show the SVM algorithm accuracy classify the types of bananas in a row of features of color, texture, shape are $41.67 \%, 33.3 \%, 8.3 \%$. And the results of the classification of Banana species with the KNN algorithm, the best $K$ value is 2 at $55.95 \%$ color features, $58.33 \%$ texture features, and $45.24 \%$ shape features.
\end{abstract}

Keywords - image features; type of classification; KNN; SVM.

\section{PENDAHULUAN}

Penelitian terkait klasifikasi atau identifikasi tanaman sudah banyak yang melakukan, diantaranya melakukan klasifikasi atau identifikasi kematangan mentimum berdasarkan fitur warna kulit dari nilai-nilai rata-rata RGB, standar deviasi, variance[1]. Di mana saat kita melakukan identifikasi atau klasifikasi citra dapat menggunakan ekstraksi fitur citra mulai dari fitur warna dari citra RGB, fitur tekstur dari citra grayscale, dan fitur bentuk dari citra biner[2]. Selanjutnya penelitian klasifikasi tanaman juga dilakukan untuk membedakan jenis Kamboja Jepang dan Kamboja Bali berdasarkan fitur citra daun dengan algoritma backpropagation[3]. Penelitian Antonio melakukan identifikasi kematangan buah Mangga Manalagi menggunakan Naïve Bayes berdasarkan fitur citra[4].

Berikut kami tampilkan penelitian-penelitian terkait identifikasi atau klasifikasi buah ataupun tanaman berdasarkan fitur citra di Tabel 1 . 
Tabel 1. Penelitian terkait Klasifikasi dari Fitur Citra

\begin{tabular}{cc}
\hline No & Tema Penelitian \\
\hline 1 & Melakukan identifikasi kematangan buah Melon[5]
\end{tabular}

\section{Fitur dan Algoritma}

Fitur statistik (rata-rata, standar deviasi, dan lainnya) dengan algoritma SVM nilai akurasinya $76 \%$, dengan data yang digunakan 450 citra Melon (300 citra untuk training, dan 150 untuk testing)

2 Melakukan ekstraksi fitur citra daun[6] Fitur tekstur, fitur warna, dan bentuk, dan menentukan korelasi antar fitur agar dapat mengklasifikasi jenis daun

$3 \quad$ Mendeteksi kematangan pisang[7]

Fitur warna RGB dan HIS nilai-nilai rata-rata intensitas cahaya, dengan akurasi $85 \%$

$4 \quad$ Klasifikasi jenis Cabai[8]

Fitur bentuk digunakan untuk identifikais jenis Cabai dengan menghitung nilai jarak antara objek dengan City Block Distance

$5 \quad$ Klasifikasi kualitas beras[9]

$6 \quad$ Identifikasi tanaman buah[10] Dari fitur citra HSV, yang dikelaskan menjadi kelas baik, kurang dan buruk dengan ID3

\section{6 r Identifikasi tanaman buah[10]}

Dengan nilai fitur tekstur, warna, dan bentuk citra daun buah akan diidentifikasi menggunakan algoritma LVQ dengan akurasi $82 \%$

\section{Identifikasi jenis tumbuhan dari citra daun[11]}

8 Mengklasifikasikan kematangan buah Manggan[12]

Algoritma Deep Learning digunakan untuk klasifikasi tumbuhan dari citra daun yang hasil akurasinya $90,8 \%$

Citra RGB dikonversi ke HSV untuk diambil fitur nilai rata-rata HSV, skewness, kurtosis. Dan diklasifikasi tingkat kematangan mentah, cukup matang, matang, dan setengah matang dengan algoritma $\mathrm{KNN}, \mathrm{K}=2$ akurasinya $80 \%$.

9 Klasifikasi jenis penyakit pada Tebu berdasarkan Fitur tekstur dan warna dari daun diolah daun[13]

10 Mengklasifikasi kualitas pisang[14] agar dapat diidentifikasi jenis penyakit, salah satu fiturnya adalah gray level cooccurance matrix

Fitur yang digunakan dari citra pisang adalah tekstur mulai dari luas cacat, nilai rata-rata $\mathrm{RGB}$, energi, homogeneity, dan kontras, dengan algoritma jaringan syaraf tiruan hasil eksperimen akurasinya 94\%

\begin{tabular}{|c|c|c|c|c|}
\hline 11 & $\begin{array}{l}\text { Menentukan tingkat } \\
\text { Pondo[15] }\end{array}$ & kematangan buah & Salah & $\begin{array}{l}\text { Fitur dari buah salah diektraksi nilai } \\
\text { rata-rata RGB dan grayscale untuk } \\
\text { diidentifikasi tingkat kematangannya } \\
\text { dengan algoritma backpropagation dan } \\
\text { KNN. Nilai akurasi } 92 \% \text { dan } 93 \% \text {. }\end{array}$ \\
\hline
\end{tabular}

Penelitian di atas menunjukkan bahwa ada peluang besar untuk melakukan klasifikasi atau identifikasi pada tanaman berdasarkan citra berbasis komputer. Di mana pada penelitian
Zeni membuktikan bahwa klasifikasi jenis Pisang dapat dilakukan berdasarkan citra HSV yang diambil fitur nilai rata-rata HSV, skewness, dan kurtosis. Di mana jenis Pisang 
yang diklasifikasi adalah Pisang ijo, sobo pipit, tandes, raja uli, dan raja dengan algoritma KNN dan tingkat akurasinya $82 \%$. Penelitian lainnya adalah melakukan klasifikais tingkat kematangan buah Mangga Manalagi berdasarkan nilai $L^{*} a * b$ citra, oleh arif Patriot. Dan dari penelitian Zeni maka kami akan mengembangkan sistem klasifikasi jenis Pisang menjadi 7 jenis, berdasarkan fitur warna, tekstur, dan bentuk. Sedangkan algoritma yang digunakan untuk klasifikasi adalah SVM, dan KNN. Tujuan penelitian ini adalah mengklasifikasi jenis Pisang menggunakan algoritma SVM dan KNN dari fitur warna, tekstur, dan bentuk.

\section{LANDASAN TEORI}

Citra adalah suatu nilai intensitas cahaya yang berupa matrik dua dimensi. Citra RGB adalah citra yang berwarna dan setiap pikselnya terdapat komponen merah, hijau dan biru[16][17][18].

Representasi dari citra di Persamaan 1:

$$
f(x, y)=\left[\begin{array}{cccc}
f(0,0) & f(0,1) & \ldots & f(0, M-1) \\
f(1,0) & f(1,1) & \ldots & f(1, M-1) \\
f(N-10) & f(N-1,1) & \ldots & f(N-1, M-1)
\end{array}\right](1)
$$

Citra mempunyai koordinat atau piksel atau titik $\mathrm{x}, \mathrm{y}$, sehingga nilai representasi intensitas cahaya dilambangkan $\mathrm{f}(\mathrm{x}, \mathrm{y})[16][17][18]$.

Citra mempunyai nilai intensitas kedalaman $2^{8}=0-255$. Dan citra gray scale adalah citra gray level (keabu-abuan). Fitur-fitur yang diambil dari citra, diantaranya rata-rata, standar deviasi, skewness, entropi, kontras, energi, korelasi, dan homogeneity dapat dilihat dalam Persamaan 2 sampai 9.

$$
\bar{x}=\frac{\sum_{i}^{N} f(i)}{N}
$$

$$
\begin{aligned}
& S=\sqrt{\frac{\sum_{i}^{N}|f(i)-\bar{x}|^{2}}{N-1}} \\
& \text { Skewness }=\frac{\mathrm{E}(\mathrm{x}-\overline{\mathrm{x}})^{3}}{\sigma^{3}} \\
& \text { Entropi }=-\sum_{i} p(i) \cdot \log _{2} p(i)
\end{aligned}
$$

Kontras $=\sum_{i, j}|i-j|^{2} p(i, j)$

Energi $=\sum_{i, j} p(i, j)^{2}$

Correlation $=\frac{\sum_{i, j}\left(i-\bar{x}_{i}\right)\left(j-\bar{x}_{j}\right) p(i, j)}{\sigma_{i} \sigma_{j}}$

Homogeneity $=\frac{\sum_{i, j} p(i, j)}{1+|i-j|}$

\section{METODE}

Penelitian ini melakukan klasifikasi jenis Pisang menjadi 7, yaitu ambon, kepok, susu, raja, mas, raja nangka, cavendish dengan algoritma SVM dan KNN. Adapun fitur yang digunakan adalah fitur warna nilai rata-rata $R$, $\mathrm{G}, \mathrm{B}$, nilai standar deviasi $\mathrm{R}, \mathrm{G}, \mathrm{B}$, nilai skewness $\mathrm{R}, \mathrm{G}, \mathrm{B}$, dan nilai entropy $\mathrm{R}, \mathrm{G}, \mathrm{B}$. Fitur tekstur di sini nilai rata-rata grayscale, nilai standar deviasi grayscale, nilai GLCM (kontras, korelasi, energi, dan homogeneity). Fitur bentuk di sini nilai dari citra biner, yaitu: area, perimeter, metric, major axis, minor axis, dan eccentricity. Langkah dari penelitian ini adalah mengambil fitur dalam Gambar 1, dan klasifikasi jenis Pisang Gambar 2. Contoh dari fitur warna dalam Tabel 2.

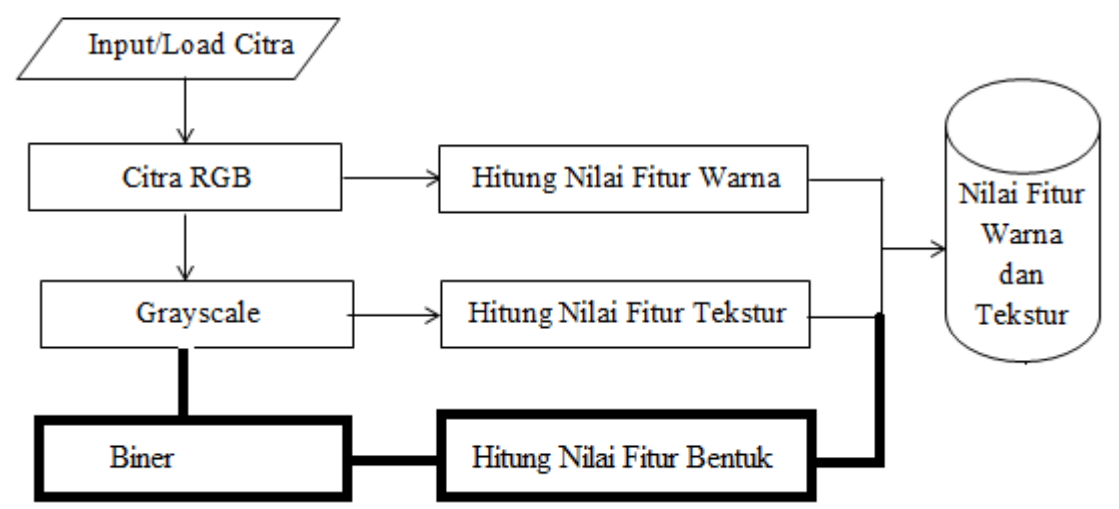

Gambar 1. Pengambilan Fitur Citra 


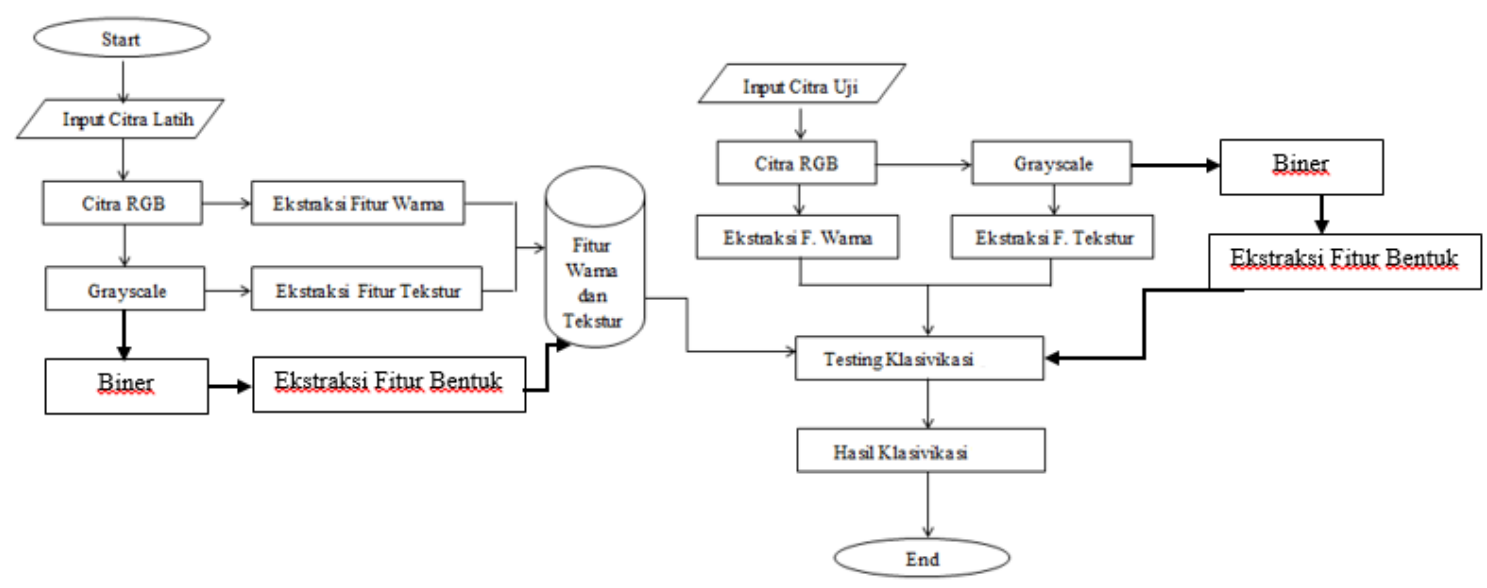

Gambar 2. Flowchart Penelitian

Tabel 2. Contoh Fitur Warna Citra

\begin{tabular}{ccccccccccccc}
\hline $\mathrm{X} 1$ & $\mathrm{X} 2$ & $\mathrm{X} 3$ & $\mathrm{X} 4$ & $\mathrm{X} 5$ & $\mathrm{X} 6$ & $\mathrm{X} 7$ & $\mathrm{X} 8$ & $\mathrm{X} 9$ & $\mathrm{X} 10$ & $\mathrm{X} 11$ & $\mathrm{X} 12$ & $\mathrm{C}$ \\
\hline 48.10 & 52.29 & 17.62 & 19.55 & 21.23 & 7.90 & 3.62 & 3.19 & 1.05 & 0.00 & 0.00 & 0.04 & 1 \\
\hline 43.81 & 44.77 & 17.24 & 20.80 & 21.78 & 5.51 & 3.41 & 3.54 & 3.09 & 0.00 & 0.00 & 0.03 & 1 \\
\hline 43.63 & 32.81 & 12.36 & 37.42 & 29.11 & 10.75 & 2.62 & 2.53 & 1.43 & 0.04 & 0.05 & 0.12 & 1 \\
\hline 52.48 & 48.40 & 12.01 & 30.87 & 27.11 & 7.87 & 1.81 & 1.58 & 0.11 & 0.05 & 0.06 & 0.17 & 1 \\
\hline 54.30 & 41.30 & 11.13 & 33.30 & 26.46 & 7.10 & 2.28 & 2.09 & 1.51 & 0.06 & 0.07 & 0.18 & 1 \\
\hline 64.08 & 56.13 & 17.21 & 31.67 & 27.79 & 11.16 & 3.42 & 0.32 & 2.46 & 0.05 & 0.06 & 0.17 & 1 \\
\hline 48.23 & 41.96 & 15.23 & 42.38 & 36.35 & 14.39 & 2.19 & 0.54 & 0.43 & 0.05 & 0.05 & 0.14 & 1 \\
\hline
\end{tabular}

Tabel 3. Citra Pisang

Jenis pisang

Pisang Ambon

Pisang Ambon

Pisang Kepok

\section{Gambar pisang}

A

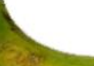


Pisang Kepok

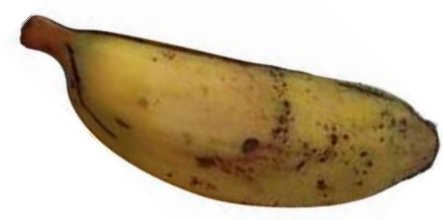

Pisang Susu

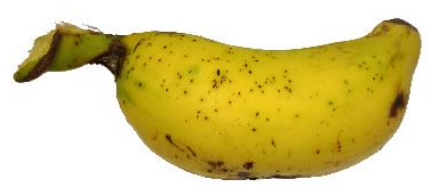

Pisang Susu

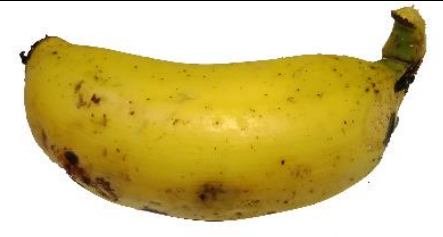

Pisang Raja

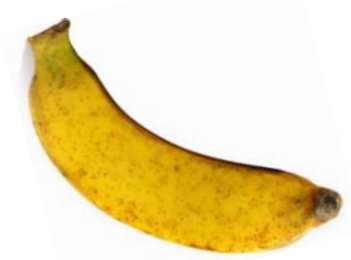

Pisang Raja

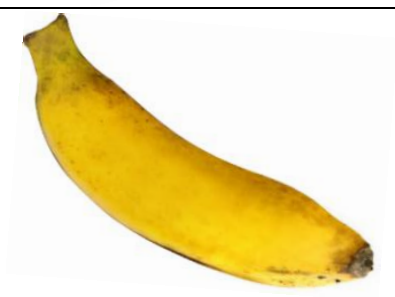

Pisang Mas

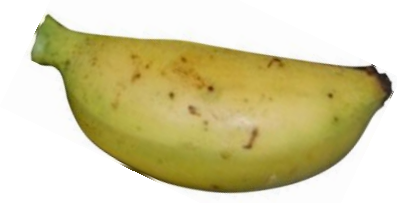


Jenis pisang

Pisang Mas

Pisang Raja Nangka

Pisang Raja Nangka

Pisang Cavendish

Pisang Cavendish

\section{Gambar pisang}

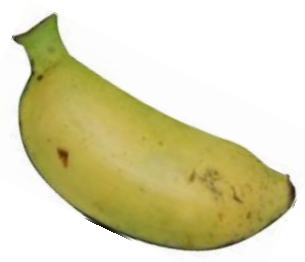

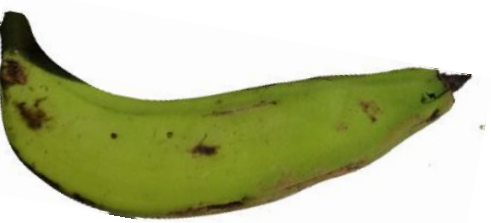
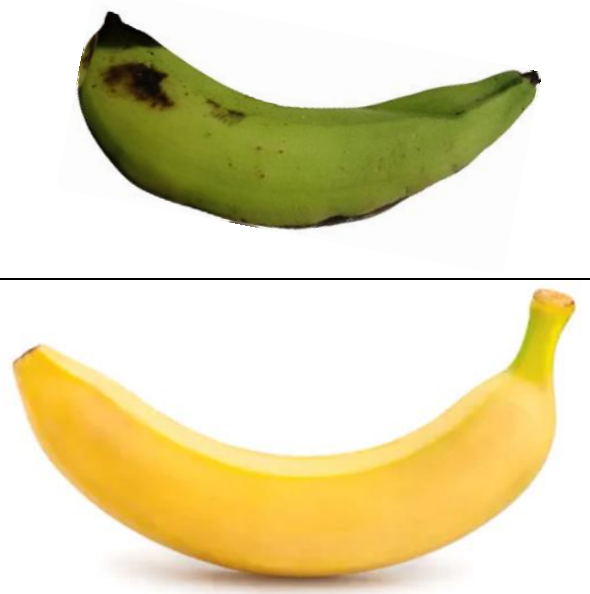


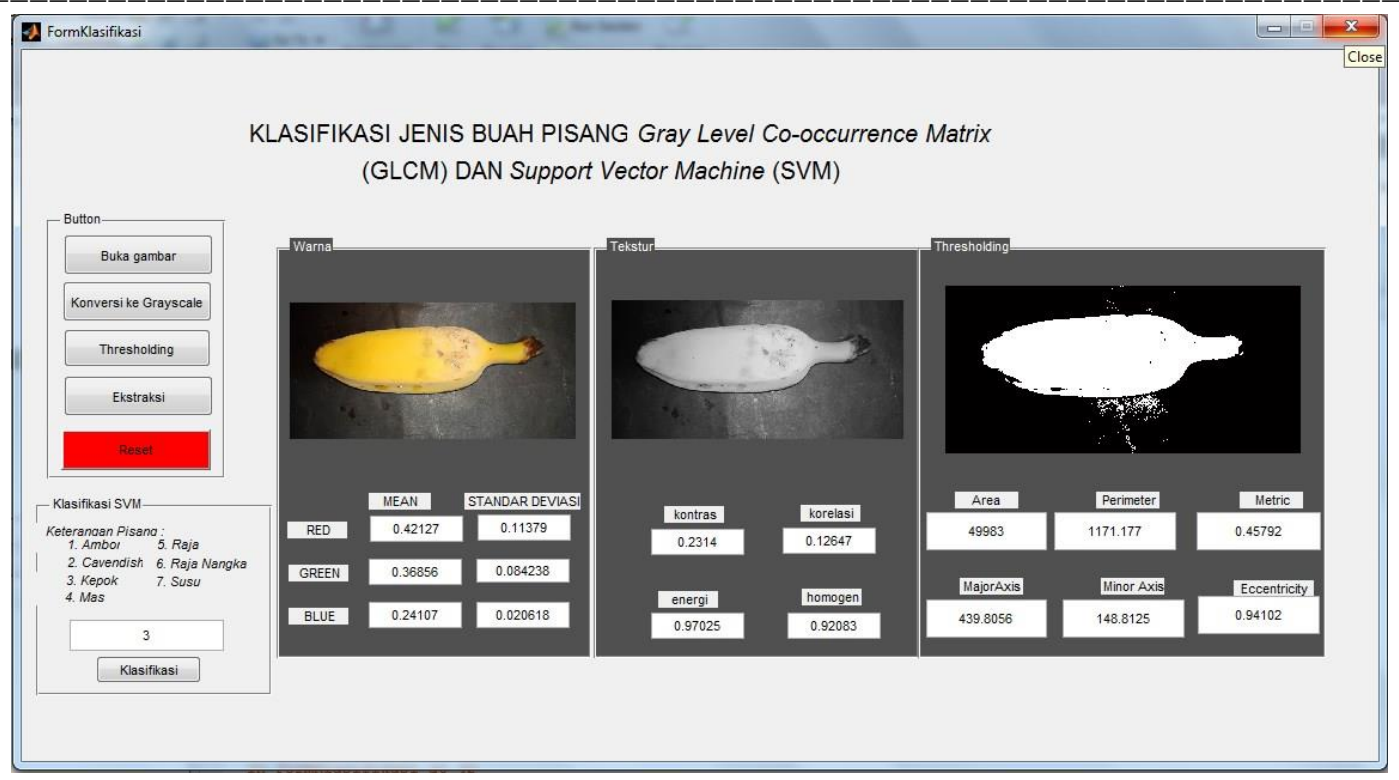

Gambar 3. Hasil Ujicoba Klasifikasi

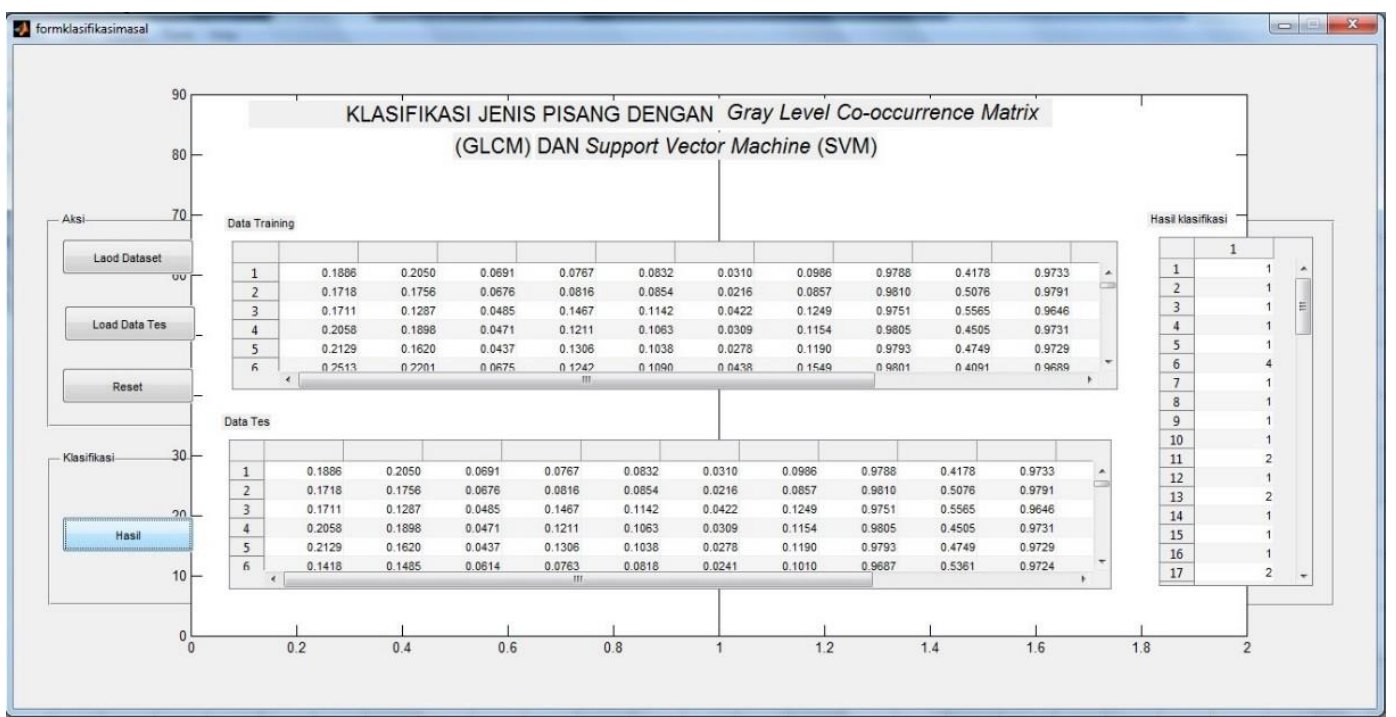

Gambar 4. Hasil Ujicoba Keseluruhan

Di mana dari Tabel 2, x1-x12 adalah ratarata $\mathrm{R}$, rata-rata $\mathrm{G}$, rata-rata $\mathrm{B}$, standar deviasi $\mathrm{R}$, standar deviasi $\mathrm{G}$, standar deviasi $\mathrm{B}$, skewness $\mathrm{R}$, skewness $\mathrm{G}$, skewness $\mathrm{B}$, entropy $\mathrm{R}$, entropy $\mathrm{G}$, entropy $\mathrm{B}$, dan $\mathrm{C}$ adalah kelas. Masing-masing kelas disimbolkan 1-7 (ambon, kepok, susu, raja, mas, raja nangka, cavendish). Contoh dari citra yang diteliti dalam Tabel 3.

\section{HASIL DAN PEMBAHASAN}

Tampilan dari hasil ujicoba klasifikasi jenis Pisang per buah dalam Gambar 3. Dan hasil ujicoba klasifikasi secara keseluruhan data dalam Gambar 4.

Di mana proses klasifikasi atau identifikasi citra, hal utama yang sangat berpengaruh adalah citra input. Beberapa penelitian ini citra input kurang baik, yaitu menghilangkan background. Sehingga hasil akurasi dari proses klasifikasi sangat buruk. Hasil ujicoba klasifikasi jenis Pisang dengan algoritma SVM dan KNN dapat dilihat dalam Tabel 4. Dan dapat dilihat bahwa pada algoritma SVM fitur warna sangat tinggi akurasinya dalam klasifikasi 41,67\%. Sedangkan algoritma KNN fitur tekstur sangat tinggi dalam klasifikasi dengan $\mathrm{K}=258,33 \%$.

Tabel 4. Hasil Ujicoba

\begin{tabular}{ccccc}
\hline & & \multicolumn{3}{c}{ Akurasi (\%) Fitur } \\
\cline { 3 - 5 } No & Algoritma & Bentuk & Tekstur & Warna \\
\hline 1 & KNN, K=2 & 45,24 & 58,33 & 55,95 \\
\hline 2 & KNN, K=3 & 33,33 & 44,05 & 44,05 \\
\hline 3 & KNN, K=4 & 29,76 & 47,62 & 42,86 \\
\hline 4 & KNN, K=5 & 27,38 & 41,67 & 42,86 \\
\hline
\end{tabular}




\begin{tabular}{ccccc}
\hline & & \multicolumn{3}{c}{ Akurasi (\%) Fitur } \\
\cline { 3 - 5 } No & Algoritma & Bentuk & Tekstur & Warna \\
\hline 5 & KNN, K=6 & 33,33 & 45,24 & 39,29 \\
\hline 6 & SVM & 8,3 & 33,3 & 41,67 \\
\hline
\end{tabular}

\section{KesIMPULAN}

Hasil klasifikais jenis Pisang dengan algoritma SVM yang paling baik adalah fitur warna 41,67\%. Hasil klasifikasi jenis Pisang dengan algoritma $\mathrm{KNN}, \mathrm{K}=2$ nilai fitur tekstur paling baik hasil akurasinya 58,33\%.

\section{DAFTAR PUSTAKA}

[1] Yuda Permadi, Murinto, "Aplikasi Pengolahan Citra untuk Identifikasi Kematangan Mentimun Berdasarkan Tekstur Kulit Buah Menggunakan Metode Ekstraksi Ciri Statistik," Jurnal Informatika, pp. 1028-1038, 2015.

[2] Sugiartha, I Gusti Rai Agung, "Ekstraksi Warna, Tekstur dan Bentuk untuk Image Retrieval," in Seminar Nasional Teknologi Informasi dan Multimedia, Yogyakarta, 2016.

[3] Sapriani Gustina, Abdul Fadlil, Rusydi Umar, "Identifikasi Tanaman Kamboja menggunakan Ekstraksi Ciri Citra Daun dan Jaringan Syaraf Tiruan," in Seminar Nasional Ilkom , 2016.

[4] Antonio Ciputra, De Rosal Ignatius Moses Setiadi, Eko Hari Rachmawanto, Ajib Susanto, "KLASIFIKASI TINGKAT KEMATANGAN BUAH APEL MANALAGI DENGAN ALGORITMA NAIVE BAYES DAN EKSTRAKSI FITUR CITRA DIGITAL," Jurnal SIMETRIS, vol. 9, no. 1, pp. 465-472, 2018.

[5] Agung Prayoga, Hilmy Abidzar Tawakal, Reza Aldiansyah, "Pengembangan Metode Deteksi Tingkat Kematangan Buah Melon Berdasarkan Tekstur Kulit Buah dengan Menggunakan Metode Ekstraksi Ciri Statistik SVM (Support Vector Machine)," Jurnal Teknologi Terpadu, 2018.

[6] Yuita Arum sari, ratih Kartika dewi, Chastine Fatichah, "SELEKSI FITUR MENGGUNAKAN EKSTRAKSI FITUR BENTUK, WARNA, DAN TEKSTUR DALAM SISTEM TEMU KEMBALI CITRA DAUN," Juti, pp. 1-8, 2014.
[7] Indarto, Murinto, "Deteksi Kematangan Buah Pisang Berdasarkan Fitur Warna Citra Kulit Pisang Menggunakan Metode Transformasi Ruang Warna HIS," JUITA, vol. 5, no. 1, pp. 15-21, 2017.

[8] Frita Devi Anggraini, Sutojo T., "Identifikasi Jenis Citra Cabai Menggunakan Klasifikasi City Block Distance dengan Fitur Bentuk sebagai Ektraksi Ciri," Skripsi.

[9] Arissa Aprilia Nurcahyani, Ristu Saptono, "Identifikasi Kualitas Beras dengan Citra Digital," Scientific Journal of Informatics, pp. 63-72, 2015.

[10] Sutarno, Rouzan Fiqri Abdullah, Rossi Passarella, "Identifikasi Tanaman Buah Berdasarkan Fitur Bentuk, Warna dan Tekstur Daun Berbasis Pengolahan Citra dan Learning Vector Quantization (LVQ)," in Annual Research Seminar (ARS), 2017.

[11] Sarirotul Ilahiyah, Agung Nilogiri, "Implementasi Deep Learning pada Identifikasi Jenis Tumbuhan Berdasarkan Citra Daun Menggunakan Convolutional Neural Network," Justindo, pp. 49-56, 2018.

[12] Husnul Khotimah, Nur Nafi'iyah, Masruroh, "Klasifikasi Kematangan Buah Mangga Berdasarkan Citra HSV dengan KNN," Jurnal Elektronika Listrik dan Teknologi Informasi Terapan, pp. 1-4, 2020.

[13] Evy Kamilah Ratnasari, Raden Venantius Hari Ginardi, Chastine Fatichah, "Klasifikasi Penyakit Noda pada Citra Daun Tebu Berdasarkan Ciri Tekstur dan Warna Menggunakan SegmentationBased Gray Level Cooccurrence Matrix dan Lab Color Moments," Register, pp. 17, 2017.

[14] Yanuar Putu Wiharja, Agus Harjoko, "Pemrosesan Citra Digital untuk Klasifikasi Mutu Buah Pisang Menggunakan Jaringan Syaraf Tiruan," IJEIS, vol. 4, no. 1, pp. 57-68, 2014.

[15] Pawit Rianto, Agus Harjoko, "Penentuan Kematangan Buah Salak Pondoh Di Pohon Berbasis Pengolahan Citra Digital," IJCCS, vol. 11, no. 2, pp. 143154, 2017.

[16] A. Kadir, Teori dan Aplikasi Pengolahan 
Citra, Yogyakarta: Andi, 2013.

[17] E. Prasetyo, Pengolahan Citra Digital dan Aplikasinya Menggunakan Matlab, Yogyakarta: Andi, 2011.

[18] D. Putra, Pengolahan Citra Digital, Yogyakarta: Andi, 2010.

[19] Zeni Dwi Lestari, Nur Nafi'iyah, Purnomo Hadi Susilo, "Sistem Klasifikasi Jenis Pisang Berdasarkan Ciri Warna HSV Menggunakan Metode K-NN," in Seminar Nasional Teknologi Informasi dan Komunikasi, Madiun, 2019.

[20] Arif Patriot Sri Pamungkas, Nur
Nafi'iyah, Nur Qomariyah Nawafilah, "KNN Klasifikasi Kematangan Buah Mangga Manalagi Menggunakan L*A*B dan Fitur Statistik," Jurnal Ilmu Komputer dan Desain Komunikasi Visual, vol. 4, no. 1, pp. 1-8, 2019. 